\title{
Normatização dos Equipamentos e Técnicas para a Realização de Avaliação Eletrofisiológica Invasiva de Pacientes com Arritmias Cardíacas
}

\author{
Coordenador \\ Jorge Ilha Guimarães
}

Editores

Eduardo Sosa (SP); Fábio Sândoli de Brito (SP); Ivan Maia (RJ); José Carlos Pachón Mateos (SP); Júlio Gizzi(SP); Márcio Fagundes (RJ); Martino Martinelli Filho(SP); Roberto Costa(SP)

\section{Participantes}

André d'Ávila (SP); Adalberto Lorga Filho(SP);

Anísio Pedrosa (SP); Álvaro Barros da Costa (RN); Ayrton Peres (DF); César Grupi (SP);

Cláudio Cirenza (SP); Dalmo Moreira (SP);

Dário Sobral (PE); Denise Hachul(SP);

Eduardo D'Andréa(RJ); Epotamenides M. GoodGod(MG);

Guilherme Fenelon(SP); Gustavo GlotzLima(RS);

Hélio Brito (MG); José Carlos Moura Jorge (PR);

José Carlos de Andrade (SP); José Carlos Ribeiro(RJ);

João Pimenta (SP); José Tarcísio de Vasconcelos (SP);

Leandro Zimerman(RS); Márcio Fagundes (RJ);

Márcio Figueiredo(SP); Ney Valente(SP);

Paulo Medeiros (SP); Reynaldo Castro Miranda (MG);

Ricardo Kunyioshi(ES); Roberto Sá (RJ);

Sérgio G. Rassi (GO); Sérgio Siqueira(SP);

Silas Galvão (SP); Silvana Nishioka (SP);

Tereza Grillo(MG); Thiago da Rocha Rodrigues(MG); Washington Maciel(RJ)

\section{Introdução}

A utilização dos estudos eletrofisiológicos na prática clínica resultou em um grande progresso na abordagem de pacientes com arritmias cardíacas. Nestes últimos 10 anos, houve um grande avanço não só do ponto de vista tecnológico, mas, principalmente, no sentido de um maior conheci- mento dos mecanismos dessas arritmias, propiciando uma abordagem mais efetiva, diagnóstica e terapêutica.

Desde a última recomendação do DAEC/SBC sobre indicações dos estudos eletrofisiológicos, muito se tem aprendido pelos inúmeros ensaios clínicos publicados na literatura, tornando necessária uma revisão atual dessas indicações.

\section{Diretrizes Técnicas para o Estudo Eletrofisiológico}

\section{Características do laboratório}

Recursos hospitalares e equipamentos necessários

- Realização do exame obrigatoriamente em ambiente hospitalar.

- Equipamento de hemodinâmica ou arco móvel de radiologia.

- Recomendação de equipamentos que minimizem a exposição à irradiação ionizante.

- Polígrafo de eletrofisiologia com um mínimo de seis canais intracavitários.

- Estimulador cardíaco com capacidade de gerar estímulos elétricos básicos e, no mínimo, três extra-estímulos.

- Marcapasso cardíaco temporário.

- Dois cardioversores-desfibriladores externos.

- Um oxímetro de pulso.

- Uma bomba de infusão.

- Material de ressuscitação cardiopulmonar.

Recursos humanos

- Médico responsável pelo procedimento, que deve ter o certificado de habilitação em eletrofisiologia clínica invasiva, conferido pelo DAEC.

- Um segundo médico, o $1^{\circ}$ auxiliar, com conhecimento em eletrofisiologia cardíaca.

- Um médico anestesista para administrar a sedação.

- Uma enfermeira(o) ou técnica(o) de enfermagem. 